\title{
Amygdala Neurons Mediate Acquisition But Not Maintenance of Instrumental Avoidance Behavior in Rabbits
}

\author{
Amy Poremba ${ }^{1}$ and Michael Gabriel ${ }^{2}$ \\ ${ }^{1}$ Laboratory of Neuropsychology, National Institute of Mental Health, Bethesda, Maryland 20892, and 2Department of \\ Psychology and the Beckman Institute, University of Illinois, Urbana, Illinois 61801
}

\begin{abstract}
Whereas the amygdala is generally understood to be involved in aversively motivated learning, the specific associative function of the amygdala remains controversial. This study addressed the amygdalar role in mediation of discriminative instrumental avoidance learning of rabbits. Bilateral microinjection of the GABA receptor agonist muscimol centered in the basolateral nucleus of the amygdala was given to inactivate amygdalar neurons at each of three stages of acquisition. The absence of behavioral learning in rabbits trained immediately after amygdalar inactivation confirmed previous results with electrolytic lesions. The absence of savings during training after muscimol had become ineffective indicated an amygdalar role in the establishment of acquisition-relevant neural plasticity, not simply in the expression of the learned response. A time-limited role of the
\end{abstract}

amygdala in instrumental avoidance learning was indicated by the finding that intra-amygdalar muscimol failed to disrupt performance of the well-established avoidance response. The passage of time alone (with no training trials) was sufficient to reduce amygdalar involvement in response performance. These results and demonstrations that other limbic system areas make time-limited contributions to learning indicate that the amygdala is part of a larger intermediate memory system that supports learning and performance before habit consolidation.

Key words: muscimol; $G A B A_{A}$ agonist; temporary lesion; fiber-sparing lesion; rabbits; instrumental learning; avoidance learning; discriminative conditioning; retention
Participation of the amygdala in aversively motivated learning is well established in animals and humans (for review, see Adolphs et al., 1995; Gallagher and Chiba, 1996; Maren and Fanselow, 1996; McGaugh et al., 1996; Davis, 1997; LeDoux and Muller, 1997; Phelps and Anderson, 1997; Cahill and McGaugh, 1998). Yet, controversy remains concerning the specific character of amygdalar involvement in learning.

One current issue concerns whether the amygdala is a key site of associative plasticity for behavioral acquisition or only for the behavioral expression of plasticity (Miserendino et al., 1990; Helmstetter and Bellgowan, 1994; Muller et al., 1997; Quirk et al., 1997). An additional issue concerns whether the amygdala contributes to learning only transiently, in early training stages (Brady et al., 1954; Fonberg et al., 1962; Horvath, 1963; Thatcher and Kimble, 1966; Parent et al., 1992; Roozendaal et al., 1993; Gall et al., 1998), or is involved throughout acquisition and during maintained performance (Weisz et al., 1992; Kim and Davis, 1993; Lee et al., 1996; Maren et al., 1996; Maren, 1998).

Disagreement on this issue may be related to the procedure used to establish learning. Thus, Pavlovian aversive conditioning involves a constant incidence of the unconditioned stimulus (US) during training. In contrast, performance of the learned response prevents US delivery during active avoidance conditioning. Because the subject's instrumental behavior reduces the number of US presentations, conditioned fear (and the relevance of the amygdala to instrumental performance) might be expected to

Received Feb. 8, 1999; revised Aug. 10, 1999; accepted Aug. 18, 1999.

This research was supported by National Institutes of Health Grant NS26736 and by National Science Foundation Grant BIR 9504842 to M.G.

Correspondence should be addressed to Dr. Michael Gabriel, University of Illinois, Beckman Institute, 405 North Mathews, Urbana, IL 61801. E-mail: mgabriel@s.psych.uiuc.edu.

Copyright (C) 1999 Society for Neuroscience 0270-6474/99/199635-07\$05.00/0 diminish. In more cognitive terms, well-trained subjects may make avoidance responses on the basis of neural representations of the conditional stimulus (CS) - shock and response-shock contingencies. Apprehension of these contingencies could be the basis for a lessening of fear during training.

These considerations raise the possibility that the amygdalar contribution to instrumental avoidance learning occurs primarily during the initial conditioning trials, as fear is conditioned to US-predictive cues. Compatible with this idea are findings that amygdalar neuronal ensembles rapidly developed massive training-induced neuronal activity (TIA) as rabbits learned to avoid shock by locomoting in response to a shock-predictive tone $(\mathrm{CS}+)$ and to ignore a different, nonpredictive tone (CS-). Yet the TIA diminished as learning reached the asymptote and as overtraining was administered (Maren et al., 1991). This diminution suggested a time-limited involvement of the amygdala in relation to the acquisition of the avoidance behavior.

Unfortunately, this evidence is not definitive, because initial increases followed by decreases of amygdalar neuronal and hemodynamic activation have also been noted during Pavlovian conditioning (Quirk et al., 1997; Buchel et al., 1998; LaBar et al., 1998). Thus a more definitive resolution of this issue will require converging evidence from other approaches, such as studies of effects of lesions.

Permanent amygdalar lesions blocked learning and prevented the development of TIA in the limbic (anterior and medial dorsal) thalamic nuclei and in related areas of the cingulate cortex (Poremba and Gabriel, 1997), areas shown previously to be essential for discriminative avoidance learning (Gabriel, 1993). These results indicated a necessary involvement of the amygdala in discriminative instrumental avoidance learning and in the elaboration of cingulothalamic learning-relevant neuronal plasticity. 
Here, the amygdala was inactivated temporarily by microinjecting intra-amygdalar muscimol, an agonist of type A GABA $\left(\mathrm{GABA}_{\mathrm{A}}\right)$ receptors (Matsumoto, 1989). Performance during the first training session immediately after fiber-sparing amygdalar inactivation determined whether the inactivation would block learning as did permanent electrolytic lesions. The assessment of savings after amygdalar recovery addressed whether the amygdala engenders learning-relevant associative plasticity or is involved only in the behavioral expression of plasticity. Inactivation after various amounts of training addressed the issue of continuous or transient involvement of the amygdala during training and whether amygdalar disengagement, if found, requires repetition of training trials or merely the passage of time after acquisition.

Parts of this paper have been published previously (Poremba and Gabriel, 1995).

\section{MATERIALS AND METHODS}

Subjects, surgery, and data collection. The subjects were 26 male New Zealand White rabbits weighing $1.5-2.0 \mathrm{~kg}$ on delivery to the laboratory and maintained in the American Association for Accreditation of Laboratory Animal Care-approved Beckman Institute Vivarium on water and rabbit chow available ad libitum. After a minimum period of $48 \mathrm{hr}$ for adaptation to living cages, each rabbit underwent surgery for implantation of six fixed-position electrodes for chronic recording of multiunit neuronal activity and stainless-steel guide cannulas for intra-amygdalar microinjection of muscimol. Recording electrodes were placed in the medial geniculate nucleus, the anterior ventral thalamic nucleus, and the medial dorsal thalamic nucleus. The neuronal data are to be presented in a separate report.

Surgical anesthesia was induced by subcutaneous injection $(1 \mathrm{ml} / \mathrm{kg}$ of body weight) of a solution containing $60 \mathrm{mg} / \mathrm{ml}$ ketamine $\mathrm{HCl}$ and 8 $\mathrm{mg} / \mathrm{ml}$ xylazine, followed by hourly injections of $1 \mathrm{ml}$ of the solution. The anesthetized rabbits were placed in a head clamp (David Kopf Instruments) for stereotaxic implantation of the electrodes and the guide cannulas (Girgis and Shih-Chang, 1981). The guide cannulas were manufactured from 22 gauge stainless-steel hypodermic tubing, through which injection cannulas were inserted for infusion of muscimol. The injection cannulas, manufactured from 28 gauge stainless-steel hypodermic tubing, extended $1 \mathrm{~mm}$ below the length of the permanently implanted guide cannula into the injection target site in the basolateral nucleus of the amygdala. The stereotaxic coordinates from bregma used for the injection target site were as follows: anteroposterior, $0.7 \mathrm{~mm}$; lateral, $\pm 5.5 \mathrm{~mm}$; and ventral, $16.0 \mathrm{~mm}$. Details of the electrode manufacture, implantation, and recording procedures are provided elsewhere (Gabriel et al., 1995).

Histology and assessment of injection size. After completion of testing, a solution of $0.2 \%$ cresyl violet dye was injected, as described above, to assess the spread of the injection in surrounding neural tissue. The injection was followed by death via an overdose of sodium pentobarbital. Transcardiac perfusion with normal saline and $10 \%$ formalin was administered as the rabbits entered deep anesthesia. The brains were frozen and sectioned at $40 \mu \mathrm{m}$, and the sections containing the cannula and electrode tracks were photographed while still wet (Fox and Eichman, 1959). Every fifth section through the areas containing the cannula tracks was saved to assess placement of the cannulas and the spread of the dye injection. After drying, all of the sections were processed with a metachromatic Nissl and myelin stain (Donovick, 1974).

Avoidance conditioning and amygdalar inactivation. The rabbits were allowed to recover for 7-10 d before the administration of discriminative avoidance training. Training was given as the rabbits occupied a runningwheel apparatus designed for conditioning of small animals (Brogden and Culler, 1936). The wheel was contained in a shielding chamber in a room adjacent to that housing the equipment for data collection. An exhaust fan and a white-noise source in the chamber produced a masking noise $\left(70 \mathrm{~dB}\right.$ re $20 \mu \mathrm{N} / \mathrm{m}^{2}$; rise time $\left.=3 \mathrm{msec}\right)$. Two pure tones of different acoustic frequency $(1$ or $8 \mathrm{kHz}$; duration $=500 \mathrm{msec} ; 85 \mathrm{~dB}$ re $20 \mathrm{~N} / \mathrm{m}^{2}$; rise time $=3 \mathrm{msec}$ ) were played through a loudspeaker attached to the chamber ceiling directly above the wheel. One of the tones was assigned as the positive $\mathrm{CS}$ or $\mathrm{CS}+$. A foot-shock US was delivered $5 \mathrm{sec}$ after the onset of the CS + . The US was a constant AC current (1.5-2.5 mA) delivered through the grid floor of the conditioning apparatus. The rabbits learned to avoid the US by stepping or hopping in response to the $\mathrm{CS}+$, thereby inducing wheel rotation. A rotation of $2^{\circ}$ or more was required for prevention of US delivery. The other tone, the negative CS (CS-), was not followed by the US, and the rabbits learned to ignore the CS-. Although the required response was minimal, all rabbits learned to make ample locomotor-conditioned responses (CRs), as reported in Results.

Before training, each rabbit received two sessions of preliminary training $(\mathrm{PT})$. In the first $\mathrm{PT}$ session, the tones to be used as CS + and $\mathrm{CS}-$ were presented in an irregular sequence, each 60 times, without the foot-shock US. In the second PT session, the tones and the US were presented in an explicitly unpaired manner (Rescorla, 1967; Gabriel, 1993). The PT sessions provided baseline data for detecting associative changes in behavioral and neural responses brought about by pairing of the CS and the US during training. Each subject was trained and tested at approximately the same time each day.

On the day after the second $\mathrm{PT}$ session, all rabbits received either 0.5 $\mu \mathrm{l}$ of muscimol $\left(\mathrm{GABA}_{\mathrm{A}}\right.$ agonist; concentration $=1.0 \mu \mathrm{mol}$; reconstituted with sterile $0.9 \%$ PBS) or sterile PBS (0.9\%). The injections were made bilaterally at a rate of $0.4 \mu \mathrm{l} / \mathrm{min}$, using a 28 gauge injection cannula attached through saline-filled polyethylene tubing to a $25 \mu \mathrm{l}$ syringe held in an infusion pump (Razel Instruments). The injection solution was separated from the saline by a $2 \mu$ l volume of air. After the injection, the cannula remained in the injection site for $1.5 \mathrm{~min}$.

The injections (muscimol or saline) were given 20-30 min before initiation of avoidance training. Experience in this study (see Results) corroborated recent findings (Li et al., 1999) indicating that behavioral and neuronal changes induced by muscimol endure for $4-6 \mathrm{hr}$ after injection. Rabbits given saline or muscimol were assigned to a saline first group and a muscimol first group, respectively. The first session of avoidance training involved the presentation of 240 conditioning trials, 120 trials with the CS + (followed by the US on non-CR trials) and 120 trials with the $\mathrm{CS}-$. The $\mathrm{CS}+$ and $\mathrm{CS}-$ trials were presented in an irregular, quasirandom sequence. The use of 240 trials doubled the usual number of trials given per training session in previous studies. An increased number of trials was used to obtain reliable discriminative learning in all subjects during the first training session. To render the data comparable with the data of studies with 120-trial sessions, the 240-trial session was treated as two separate 120-trial sessions, labeled sessions A and B. Training on the second day also involved two 120-trial sessions, labeled sessions $\mathrm{C}$ and $\mathrm{D}$, but no injections were given before training on the second day. The intertrial interval was $8,13,18,23$, or 28 sec, these values occurring in an irregular order. Responses during the intertrial interval reset the interval. The average time to complete a 120 -trial session ranged from 1.0 to $3.0 \mathrm{hr}$.

Subsequent daily training sessions consisted of 120 trials $(60 \mathrm{CS}+$ trials and $60 \mathrm{CS}-$ trials). These sessions were administered daily until a behavioral criterion was reached. The behavioral criterion required that the percentage of behavioral responses to the CS + exceed the percentage of responses to the CS- by $60 \%$ or more in two consecutive sessions. Past experience indicated that asymptotic performance is attained with this criterion; i.e., performance levels yielded by this criterion are not exceeded during further (postcriterial) overtraining.

Six sessions of "overtraining" (120 trials per consecutive daily session) were administered after the rabbits reached criterion. Before the fourth session of overtraining, each rabbit received the injection (muscimol or saline) not given before the first training session. No injections were given before the fifth session of overtraining. Before the sixth session of overtraining, the rabbits were given the injection (muscimol or saline) not received before the fourth session of overtraining.

Each rabbit then received either $7 \mathrm{~d}$ of rest in home cages or seven additional standard overtraining sessions. On the day after the final rest or overtraining session, the rabbits were given the injection (muscimol or saline) not given previously. This injection was followed immediately by an additional standard training session. Two additional training sessions were given on the following days, the second of these preceded by an injection of saline or muscimol, whichever had not been received previously. The training and injection sequence is depicted in Figure 1.

Note that the avoidance learning described here is not "traumatic" avoidance learning. Traumatic learning, which is very resistant to extinction, has been observed in studies with canine subjects involving very high shock levels (Solomon and Wynne, 1954). The avoidance learning administered in this study is nontraumatic and rapidly extinguished as shown in several studies (e.g., Hart et al., 1997).

Analysis of the data. The data were submitted to factorial, repeated measures ANOVA using the $2 \mathrm{~V}$ program (BMDP Statistical Software). 
Saline First Grp Muscimol First Grp

\begin{tabular}{|c|c|c|}
\hline First Training Day & Saline Injection & Muscimol Injection \\
\hline & Sessions A \& B & Sessions A \& B \\
\hline \multirow[t]{3}{*}{ Second Training Day } & No Solution Injected & No Solution Injected \\
\hline & Sessions C \& D & Sessions C \& D \\
\hline & $\begin{array}{l}\text { Training continued ur } \\
\text { reached behavioral c } \\
\text { by three days of over }\end{array}$ & $\begin{array}{l}\text { ntil each animal } \\
\text { riterion followed } \\
\text { training }\end{array}$ \\
\hline Fourth Overtraining Day & Muscimol Injection & Saline Injection \\
\hline Fifth Overtraining Day & No Injection & No Injection \\
\hline \multirow[t]{2}{*}{ Sixth Overtraining Day } & Saline Injection & Muscimol Injection \\
\hline & $\begin{array}{l}\text { Seven Additional } \\
\text { Rest Days }\end{array}$ & $\begin{array}{l}\text { Seven Additional } \\
\text { Overtraining Days }\end{array}$ \\
\hline Add. Overtraining Day & Muscimol Injecion & Saline Injection \\
\hline Add. Overtraining Day & No Injection & No Injection \\
\hline Add. Overtraining Day & Saline Injection & Muscimol Injection \\
\hline
\end{tabular}

Figure 1. A portrayal of the experimental training sequence. Double training sessions of 120 trials each, 60 with the CS+ and 60 with the CS-, were administered on the First Training Day and the Second Training Day. Each daily training session after the first $2 \mathrm{~d}$ involved 120 training trials, 60 with the $\mathrm{CS}+$ and 60 with the $\mathrm{CS}-$.

The $\alpha$ level for all testing was set at $p<0.05$. Correction of the $F$ test because of disconformity of the data with the sphericity assumption of these analyses was performed as needed following the procedure of Huynh and Feldt (1976). Factors yielding significant $F$ ratios were further analyzed using simple-effect tests following procedures described by Winer (1962, chapter 7). The analyses had a between-subject factor of group (lesion, control) and orthogonal repeated measures factors of training stage or session (as specified for each analysis in Results) and stimulus (two levels, $\mathrm{CS}+/ \mathrm{CS}-$ ).

\section{RESULTS}

\section{The first day of training}

Rabbits given muscimol failed to exhibit significant discriminative avoidance learning in the extended initial training session. Significant learning did not occur during the first 120 trials (session A) or during the second 120 trials (session B). Rabbits given saline did exhibit significant learning. These conclusions were based on an analysis with factors of group (muscimol first and saline first), session (two levels, A and B), and stimulus (two levels, $\mathrm{CS}+/ \mathrm{CS}-$ ). The analysis yielded a significant interaction of the group and stimulus factors $\left[F_{(1,24)}=14.75 ; p<0.01\right]$. Simple-effect tests showed discriminative responding in the saline first group, i.e., a significantly greater average percentage of CRs to the $\mathrm{CS}+$ than to the $\mathrm{CS}-(p<0.01)$. However, the rabbits in the muscimol first group did not respond more frequently to the $\mathrm{CS}+$ than to the $\mathrm{CS}-$ (Fig. 2, left). These results were pooled over sessions (A and B) because the session factor did not contribute to the significant interaction. Additionally, the average percentage of CRs performed by the rabbits in the muscimol first

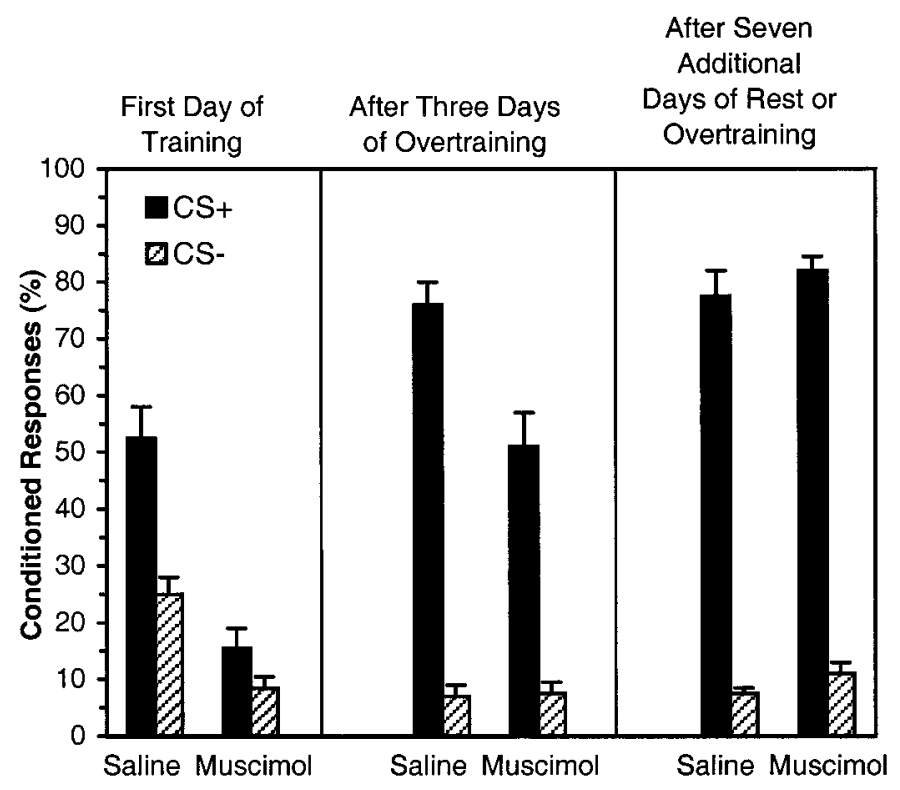

Figure 2. Percentage of conditioned responses to the CS+ (dark bars) and the CS- (hatched bars) at the indicated stages of training.

group to both the $\mathrm{CS}+$ and the $\mathrm{CS}$ - during the first training day was significantly reduced relative to the average percentage of CRs performed by the rabbits in the saline first group $(p<0.01)$.

To obtain a maximally sensitive test for learning in the muscimol first group, we analyzed the percentage of CRs in response to the $\mathrm{CS}+$ and $\mathrm{CS}-$ for three sessions: pretraining with unpaired $\mathrm{CS}$ and US presentations, session A, and session B. In agreement with the aforementioned results indicating no learning in the muscimol first group, there were no significant effects involving the session factor. However, the interaction of the session and stimulus factors did approach significance $(p=0.055)$, indicating a possible modest development of discriminative behavior in rabbits given intra-amygdalar muscimol. This outcome was perhaps to be expected, because of the inevitable variability of muscimol distribution and the possible degradation of muscimol over time during training.

The analysis of the amplitude of the avoidance CRs, measured as the number of $4^{\circ}$ wheel turns, yielded a significant main effect of the group factor $\left[F_{(1,24)}=11.05 ; p<0.01\right]$, indicating that the muscimol first group made less ample CRs than did the saline first group. The analysis of latency of the unconditioned response (UR), defined as the number of milliseconds from US onset to the first detection of wheel movement, also yielded a significant main effect of the group factor $\left[F_{(1,24)}=15.62 ; p<0.01\right]$, indicating longer latencies for the muscimol first group compared with the saline first group. There were no significant group differences for the latency of the CR, amplitude of the UR, or number of intertrial responses.

\section{The second day of training: assessment of savings}

The foregoing data indicated that intra-amygdalar muscimol given just before training blocked the development of learned behavior during the first training day. It is possible, however, that the muscimol prevented the expression of the learned behavior but that plasticity involved in coding of the association of the CSs with the US was formed during the first session of training in the presence of muscimol. If such plasticity did develop it could support an enhancement of learned responding (i.e., savings) 


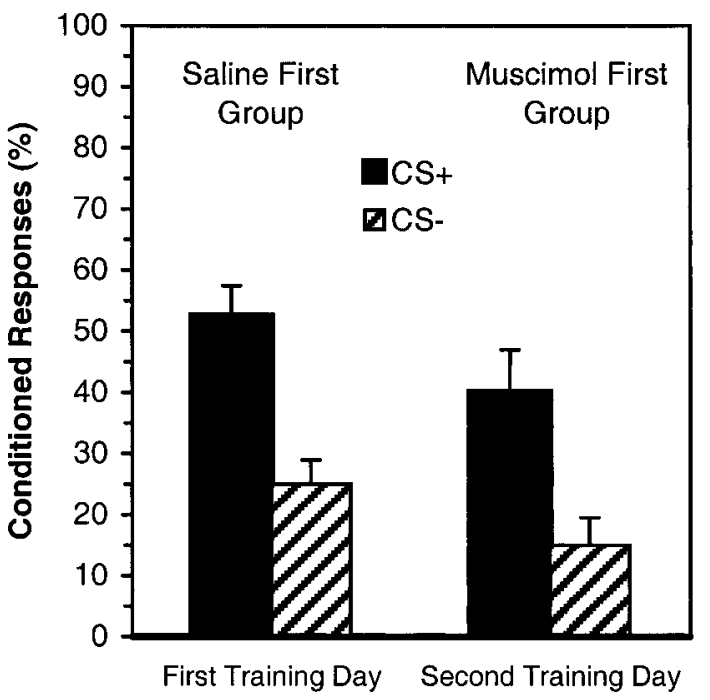

Figure 3. Percentage of conditioned responses to the CS + (dark bars) and the CS- (hatched bars) in sessions A and B (First Training Day) for the Saline First Group and in sessions C and D (Second Training Day) for the Muscimol First Group. The between-group comparison indicated that no savings occurred in the Muscimol First Group.

during the second day of training. To examine this possibility, the performance of the muscimol first group on the second day of training was compared with the first-day performance of the saline first group. There were no significant between-group differences in the percentage of CRs or in discrimination between $\mathrm{CS}+$ and $\mathrm{CS}-$ (Fig. 3). Thus, performance of the muscimol first group on the second day of training, although indicative of significant learning, was not better than the first-day performance of the saline first group and thus did not indicate savings based on exposure to the conditioning contingencies during the first day of training.

Again, the rabbits in the muscimol first group exhibited greater average UR latencies during sessions $\mathrm{C}$ and $\mathrm{D}$ than did the saline first group during sessions $\mathrm{A}$ and $\mathrm{B}$. This was indicated by a significant main effect of the group factor $\left[F_{(1,15)}=7.38 ; p<0.02\right]$.

No significant effects were found in the analyses of the remaining measures of behavioral performance: latency and amplitude of the CR, amplitude of the UR, and intertrial response incidence.

\section{Number of sessions to criterion}

The number of sessions required for the attainment of criterion for the muscimol first group (8.90) was significantly greater than that for the saline first group [5.69; $\left.F_{(1,22)}=4.92 ; p<0.04\right]$. However, the total number of sessions to criterion attainment does not yield a meaningful comparison, because the muscimol first group did not learn on the first day, because of the muscimol injection. When the first session was eliminated from the analysis for the muscimol first group, no significant effect of the muscimol first treatment on the number of sessions required for criterion attainment was found $(p=0.4105)$. These results are in accord with the conclusion that the first-day conditioning experience of rabbits in the muscimol first group did not engender savings during subsequent training without muscimol.

\section{Performance of the well-learned response}

Although intra-amygdalar muscimol did not reduce the learning rate as assessed by the number of sessions required for criterion attainment, it is possible that the muscimol injection may have

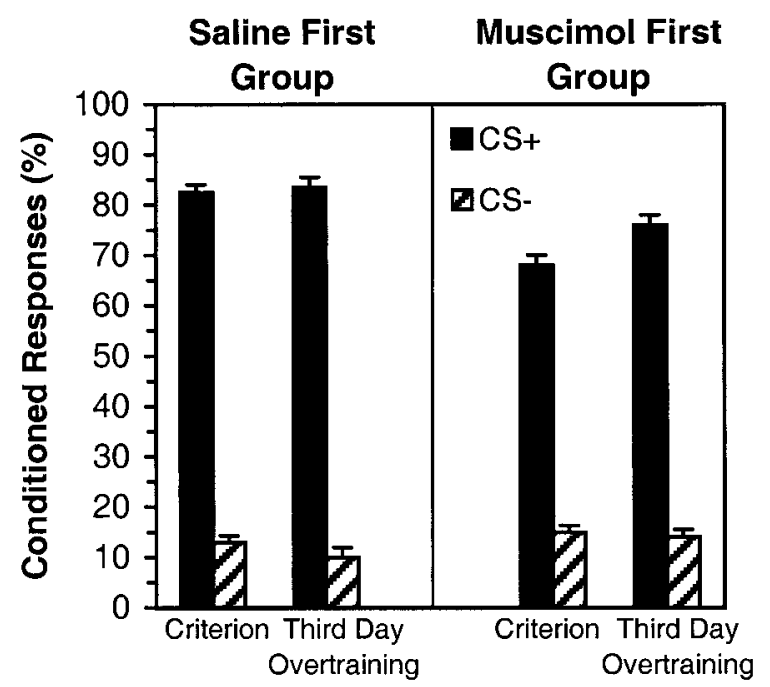

Figure 4. Percentage of conditioned responses to the $\mathrm{CS}+$ (dark bars) and the $\mathrm{CS}-$ (hatched bars) during the session of criterion attainment and the third session of overtraining for the Saline First (left) and the Muscimol First (right) groups.

affected the level of performance attained by well-trained rabbits. To evaluate this possibility, analyses of the asymptotic CR percentages in trained rabbits were performed. These analyses had factors of group (muscimol first and saline first), session (two levels, the session of criterion attainment and the third session of overtraining), and stimulus (two levels, $\mathrm{CS}+/ \mathrm{CS}-$ ). A significant interaction of the group, session, and stimulus factors was obtained $\left[F_{(5,120)}=2.60 ; p<0.04\right]$. Simple-effect tests indicated that the muscimol first group exhibited a significantly reduced percentage of CRs to CS + compared with that of the saline first group, even though the behavioral criterion had been reached by both groups after comparable numbers of training sessions $(p<$ 0.05; Fig. 4). Note that the criterion requires a particular level of discriminative, not absolute performance (see Materials and Methods). Thus, the discriminative requirement of the criterion was met, whereas the average CR percentage exhibited by the muscimol first group was only $67 \%$ in the criterial session. The saline first group performed CRs on $80 \%$ of the CS + trials, a performance level essentially the same as the criterial performance of intact rabbits in other experiments (Gabriel, 1993). However, after $3 \mathrm{~d}$ of overtraining, the CR performance of the rabbits in the muscimol first group improved, and the two groups did not differ significantly (Fig. 4). No significant effects were found for other measures of behavioral performance, including the latency and duration of the CR and the UR and the frequency of intertrial responses.

\section{Intra-amygdalar muscimol after overtraining}

The analyses had factors of group (muscimol first and saline first), agent (two levels, muscimol or saline), and stimulus (two levels, $\mathrm{CS}+/ \mathrm{CS}-$ ). The analysis of $\mathrm{CR}$ performance yielded a significant interaction of the agent and stimulus factors $\left[F_{(1.24)}=23.12\right.$; $p<0.01]$. Simple-effect tests indicated that muscimol injected after overtraining significantly reduced $\mathrm{CR}$ percentage in response to the CS+ to $50 \%$ compared with a CR percentage of $76 \%$ in the overtraining session preceded by saline injection $(p<$ 0.01; Fig. 2, middle). There were no significant effects of the agent or group factors on CR percentages in response to the CS-.

The analysis of the CR amplitude yielded a significant main 
effect indicating a continuing effect of the first muscimol injection on CR amplitude during overtraining. The amplitude of the CR was significantly reduced in the muscimol first group compared with the saline first group $\left[F_{(1,24)}=6.07 ; p<0.03\right]$. No significant effects were found in the analyses of the remaining measures of behavioral performance, including the latency of the CR, the latency and amplitude of the UR, or intertrial responses.

\section{Intra-amygdalar muscimol after 7 additional days of overtraining or rest}

This analysis had factors of activity (two groups, rabbits given $7 \mathrm{~d}$ of rest after overtraining or rabbits given 7 additional days of overtraining), agent (two levels, muscimol or saline), and stimulus (two levels, $\mathrm{CS}+/ \mathrm{CS}-$ ). There was no significant reduction in the percentage of CRs to the CS+ or CS - in the muscimol session compared with the saline session (Fig. 2, right). The rabbits given $7 \mathrm{~d}$ of rest $(n=9)$ made a significantly greater percentage of CRs to the CS+ $(83 \%)$ than did rabbits given seven sessions of overtraining $(73 \% ; n=8)$, regardless of whether muscimol or saline was injected. This result was indicated by a significant main effect of the activity factor $\left[F_{(1,12)}=5.79 ; p<0.03\right]$.

The analysis of CR amplitude yielded a significant interaction of activity and agent $\left[F_{(1,15)}=10.54 ; p<0.01\right]$. Simple-effect tests indicated that the $\mathrm{CR}$ amplitude was reduced significantly $(p<$ 0.05 ) after muscimol injection in rabbits given $7 \mathrm{~d}$ of rest compared with the average $\mathrm{CR}$ amplitude exhibited by rabbits given $7 \mathrm{~d}$ of overtraining. However, CR amplitude after saline injections was not affected by the activity factor (rest or overtraining). None of the remaining measures of behavioral performance were significantly affected by muscimol after extended overtraining or rest.

\section{DISCUSSION}

\section{Summary of findings}

Intra-amygdalar microinjection of the $\mathrm{GABA}_{\mathrm{A}}$ agonist muscimol immediately before discriminative avoidance training blocked learning on the first day of training. These results confirm previous findings with permanent lesions (Poremba and Gabriel, 1997), indicating that the learning deficit is not caused by damaged fiber systems passing through the amygdala.

Intra-amygdalar muscimol was also associated with a significantly increased latency of the rabbits' UR (the unconditioned response to the foot-shock US) as well as a significant decrease in UR and CR amplitudes, as measured by the number of $4^{\circ}$ wheel turns per response. (Permanent lesions did not significantly alter the properties of the UR, but they did reduce CR amplitude.) Compensatory changes during recovery from the permanent lesions may have mitigated the UR alterations. However, the altered UR properties in this study were not responsible for the absence of learning with muscimol present, because the rabbits learned at normative rates after muscimol had become ineffective, despite the persistence of the UR changes.

\section{The amygdala and learning-related plasticity}

Although learning occurred after muscimol had become ineffective, "savings" were not exhibited (i.e., improved performance because of the first day's training with muscimol present). As expected, rabbits given saline showed significant learning during the first training session as well as savings on the second day of training. The absence of savings in the rabbits given muscimol suggested that the neural plasticity for discriminative avoidance learning was not formed during training with muscimol present.
These results support the hypothesis that the amygdala is importantly involved in the formation of learning-relevant neural plasticity, not simply in the expression of the learned response.

The contribution of the amygdala to learning-relevant plasticity could occur whether the plasticity were formed within the amygdala itself or whether the amygdala were involved in establishing the critical plasticity in nonamygdalar areas. Demonstrations of amygdalar TIA (Pascoe and Kapp, 1985; Maren et al., 1991; Muramoto et al., 1993; Quirk et al., 1997) and plasticity in various synaptic potentiation paradigms (Chapman et al., 1990; Clugnet and LeDoux, 1990; Maren and Fanselow, 1995; McKernan and Shinnick-Gallagher, 1997; Quirk et al., 1997; Rogan et al., 1997) encourage the view that plasticity essential for discriminative avoidance learning occurs at amygdalar synapses. Nevertheless, a substantial amount of evidence indicates that the amygdala engenders learning by promoting plasticity in nonamygdalar brain substrates as well.

McGaugh et al. (1996) have presented evidence that the amygdala facilitates memory storage in nonamygdalar brain sites. Moreover, cingulothalamic TIA, which mediates attention to the $\mathrm{CS}+$ and retrieval of behavioral responses, is essential for discriminative avoidance learning (Gabriel, 1993; Freeman et al., 1996; Gabriel and Taylor, 1998). Amygdalar lesions block avoidance learning and cingulothalamic TIA development, indicating a role of the amygdala in TIA establishment (Poremba and Gabriel, 1997).

Additional data point to an amygdalar involvement in plasticity development in areas concerned with behavioral response integration and learning. For example, amygdalar inactivation in this study abolished conditioning-related reductions of UR latency, confirming the role of the amygdala in facilitation of aversively motivated conditioned and unconditioned responses such as the startle reflex and the brief-latency stress-related eyeblink response in rabbits and rats (for review, see Davis, 1997; see also Weisz et al., 1992; Canli and Brown, 1996).

The role of the amygdala in initiating learning-relevant plasticity in nonamygdalar brain areas does not imply that the amygdala is essential in all forms of learning and memory. Amygdalar lesions that blocked discriminative avoidance learning had no impact on discriminative approach learning (Smith et al., 1998). Approach learning required many more conditioning trials than did avoidance learning, cingulothalamic TIA development was comparably slow, and TIA amplitudes were significantly reduced compared with that of TIA during avoidance learning, suggesting a lesser motivational valence of the approach task. It would thus appear that TIA and behavioral learning develop without the benefit of amygdalar facilitative influences in tasks that have moderate motivational valences. In agreement with the view that amygdalar function is involved in modulating the storage of "flashbulb" memories (McGaugh et al., 1996; Cahill and McGaugh, 1998), amygdalar facilitation of stimulus- and responserelated neural plasticity appears to be recruited preferentially in learning situations that constitute "emergencies" for the involved subjects.

\section{Time-limited involvement of the amygdala}

Intra-amygdalar muscimol after overtraining moderately reduced CR performance, and muscimol after seven additional overtraining sessions (or $7 \mathrm{~d}$ of rest in a separate group of rabbits) had no effect at all. These results indicated that amygdalar processing that is essential for the early stages of learning is not critical for the performance of well-learned behavior. Because the muscimol 
injections also became ineffective after $7 \mathrm{~d}$ of rest, the gradual lessening of amygdalar involvement in performance was not caused by the repetition of training trials per se. Rather, it was set in motion by earlier training experience and occurred with the passage of time alone.

The hypothesis of a gradual lessening of amygdalar involvement in the mediation of the avoidance CR was reinforced by other findings of this study. Thus, although they attained the criterion as rapidly as saline-injected controls during postmuscimol learning in the muscimol-free state, the rabbits given muscimol suffered a significant $\mathrm{CR}$ decrement relative to that of the controls. Also, as mentioned, the UR latencies of rabbits given muscimol were greater than control latencies during the first training session and during training to criterion in the muscimolfree state. Yet, after criterion, the CR frequencies and UR latencies in rabbits given muscimol before training were not different from that in controls. Thus, the persistent effects of muscimol were time-limited, dissipating as rabbits received extended overtraining or extended rest in their living cages. It is unlikely that these effects were caused by gradually diminishing residual muscimol at amygdalar synapses, because the injection of muscimol had no effect on performance in overtrained rabbits.

It is interesting to consider the functional implications of the amygdalar time-limited involvement in learning. One interpretation states that the effect follows naturally from the role of the amygdala in initiation of learning-related plasticity in other brain areas (see above). After learning-related plasticity has been initiated, there is no longer a role for the amygdala in support of the learned behavior. Yet, on closer examination this explanation becomes unconvincing.

First, the period of training over which amygdalar processing affected the behavior was substantial. In the present study the amygdalar influence was lost only after $13 \mathrm{~d}$ of postcriterial overtraining or after $6 \mathrm{~d}$ of overtraining and $7 \mathrm{~d}$ of rest. Thus, although it is time limited, the contribution of the amygdala to discriminative avoidance behavior is long-enduring. Thus the amygdala initiates plasticity in other brain areas and also provides long-enduring support of learning and performance. The implied diversity of amygdalar function is expected because of the diverse cytoarchitecture of the amygdalar region. Functional heterogeneity of amygdalar areas has been supported in several studies (e.g., Killcross et al., 1997).

Second, nonamygdalar areas also have a time-limited role in learning, and the duration of engagement of these areas is of the same order of magnitude as the duration of amygdalar engagement. For example, combined lesions in the limbic anterior thalamic and medial dorsal thalamic nuclei administered before training blocked behavioral acquisition (see Gabriel, 1993). Lesions made after criterion attainment severely impaired retention of the avoidance response, but lesions administered after $10 \mathrm{~d}$ of overtraining had no significant impact on retention (Hart et al., 1997). Thus, whereas the integrity of the amygdala is essential for cingulothalamic plasticity development, amygdalar involvement in mediation of avoidance learning and performance, as well as the decline of that involvement, occurs in parallel with the involvement and decline of the limbic thalamic nuclei. The hippocampus has been reported to exhibit a time-limited involvement in a variety of learning processes, including declarative memory (Zola-Morgan and Squire, 1990) and Pavlovian conditioning of the rabbit eyeblink response (Kim et al., 1995; Moyer et al., 1996). The duration of hippocampal involvement in eyeblink conditioning, measured in weeks, is comparable with the duration of amygdalar and cingulothalamic involvement in instrumental avoidance conditioning.

These findings indicate that the time-limited involvement of the amygdala is one instance of the more general time-limited involvement of the limbic circuit as a whole (discussed here as including the amygdala, cingulothalamic areas, and hippocampus). The circuit's time-limited engagement modulates a wide variety of mnemonic functions, in learning situations ranging from declarative memory to instrumental and classical conditioning. It follows that unidentified areas of the brain are capable of mediating learned behavior and memory no longer served by the limbic circuit.

Time-limited involvement of particular brain areas in memory is commonly thought to indicate the occurrence of memory consolidation processes. Consolidation has been discussed chiefly in relation to forms of learning and memory that depend on the hippocampus, and an active role in mediating consolidation has been attributed to the hippocampus (e.g., Milner, 1971; Squire and Zola-Morgan, 1991; Nadel and Moscovitch, 1998). The present results indicate that discriminative avoidance learning undergoes consolidation, in the sense that it becomes progressively independent of limbic circuit structures as training continues. This learning is not dependent on the hippocampus. Other forms of nonhippocampal learning undergo consolidation (e.g., Shadmehr and Holcolmb, 1997). These considerations indicate that the amygdala and hippocampus participate in a larger limbic circuit whose contribution to conditioning and learning is timelimited. This circuit may actively mediate consolidation processes, or it may simply support behavioral acquisition and performance for an interim period until more permanent memory coding is established in nonlimbic regions. These considerations are compatible with a view of the limbic circuit as an intermediate memory system.

\section{REFERENCES}

Adolphs R, Tranel D, Damasio H, Damasio AR (1995) Fear and the human amygdala. J Neurosci 15:5879-5891.

Brady JV, Schreiner L, Geller I, Kling A (1954) Subcortical mechanisms in emotional behavior: the effect of rhinencephalic injury upon the acquisition and retention of a conditioned avoidance response in cats. J Comp Physiol Psychol 47:179-186.

Brogden WJ, Culler FA (1936) A device for motor conditioning of small animals. Science 83:269.

Buchel C, Morris J, Dolan RJ, Friston KJ (1998) Brain systems mediating aversive conditioning: an event-related fMRI study. Neuron 20:947-957.

Cahill L, McGaugh JL (1998) Mechanisms of emotional arousal and lasting declarative memory. Trends Neurosci 21:294-299.

Canli T, Brown TH (1996) Amygdala stimulation enhances the rat eyeblink reflex through a short-latency mechanism. Behav Neurosci 110:51-59.

Chapman PF, Kairiss EW, Keenan CL, Brown TH (1990) Long-term synaptic potentiation in the amygdala. Synapse 6:271-278.

Clugnet MC, LeDoux JE (1990) Synaptic plasticity in fear conditioning circuits: induction of LTP in the lateral nucleus of the amygdala by stimulation of the medial geniculate body. J Neurosci 10:2818-2824.

Davis M (1997) Neurobiology of fear responses: the role of the amygdala. J Neuropsychiatry Clin Neurosci 9:382-402.

Donovick PJ (1974) A metachromatic stain for neural tissue. Stain Technol 49:49-51.

Fonberg E, Brutkowski S, Mempel E (1962) Defensive conditioned reflexes and neurotic motor reactions following amygdalectomy in dogs. Acta Biol Exp (Warsz) 22:263-273.

Fox CA, Eichman J (1959) A rapid method for locating intracerebral electrode tracks. Stain Technol 34:39-42.

Freeman J, Cuppernell C, Flannery K, Gabriel M (1996) Contextspecific multi-site cingulate cortical, limbic thalamic, and hippocampal 
neuronal activity during concurrent discriminative approach and avoidance training in rabbits. J Neurosci 16:1538-1549.

Gabriel M (1993) Discriminative avoidance learning: a model system. In: Neurobiology of cingulate cortex and limbic thalamus: a comprehensive handbook (Vogt BA, Gabriel M, eds), pp 478-523. Boston: Birkhauser.

Gabriel M, Taylor C (1998) Prenatal exposure to cocaine impairs neuronal coding of attention and discriminative learning. Ann NY Acad Sci 846:194-212.

Gabriel M, Cuppernell C, Shenker JI, Kubota Y, Henzi V, Swanson D (1995) Mamillothalamic tract transection blocks anterior thalamic training-induced neuronal plasticity and impairs discriminative avoidance behavior in rabbits. J Neurosci 15:1437-1445.

Gall CM, Hess US, Lynch G (1998) Mapping brain networks engaged by, and changed by, learning. Neurobiol Learn Mem 70:14-36.

Gallagher M, Chiba A (1996) The amygdala and emotion. Curr Opin Neurobiol 6:221-227.

Girgis M, Shih-Chang W (1981) A new stereotaxic atlas of the rabbit brain. St. Louis: Green.

Hart M, Poremba A, Gabriel M (1997) The nomadic engram: overtraining eliminates the impairment of discriminative avoidance behavior produced by limbic thalamic lesions. Behav Brain Res 82:169-177.

Helmstetter FJ, Bellgowan PS (1994) Effects of muscimol applied to the basolateral amygdala on acquisition and expression of contextual fear conditioning in rats. Behav Neurosci 108:1005-1009.

Horvath FE (1963) Effects of basolateral amygdalectomy on three types of avoidance behavior in cats. J Comp Physiol Psychol 56:380-389.

Huynh H, Feldt LS (1976) Estimation of the box correction for degrees of freedom from sample data in randomized block and split-plot designs. J Educ Stat 1:69-82.

Killcross S, Robbins TW, Everitt BJ (1997) Different types of fearconditioned behavior mediated by separate nuclei within amygdala. Nature 388:377-380.

Kim JJ, Clark RE, Thompson RF (1995) Hippocampectomy impairs the memory of recently, but not remotely, acquired trace eyeblink conditioned responses. Behav Neurosci 109:195-203.

Kim M, Davis M (1993) Electrolytic lesions of the amygdala block acquisition and expression of fear-potentiated startle even with extensive training but do not prevent reacquisition. Behav Neurosci 107:580-595

LaBar KS, Gatenby JC, Gore JC, LeDoux JE, Phelps EA (1998) Human amygdala activation during conditioned fear acquisition: a mixed-trial fMRI study. Neuron 20:937-945.

LeDoux JE, Muller J (1997) Emotional memory and psychopathology. Philos Trans R Soc Lond [Biol] 352:1719-1726.

Lee Y, Walker D, Davis M (1996) Lack of a temporal gradient of retrograde amnesia following NMDA-induced lesions of the basolateral amygdala assessed with the fear-potentiated startle paradigm. Behav Neurosci 110:836-839.

Li CR, Mazzoni P, Andersen RA (1999) Effect of reversible inactivation of macaque lateral intraparietal area on visual and memory saccades. J Neurophysiol 81:1827-1838.

Maren S (1998) Overtraining does not mitigate contextual fear conditioning deficits produced by neurotoxic lesions of the basolateral amygdala. J Neurosci 18:3088-3097.

Maren S, Fanselow MS (1995) Synaptic plasticity in the basolateral amygdala induced by hippocampal formation stimulation in vivo. J Neurosci 15:7548-7564.

Maren S, Fanselow MS (1996) The amygdala and fear conditioning: has the nut been cracked? Neuron 16:237-240.

Maren S, Poremba A, Gabriel M (1991) Basolateral amygdaloid multiunit neuronal correlates of discriminative avoidance learning in rabbits. Brain Res 549:311-316.

Maren S, Aharonov G, Fanselow MS (1996) Retrograde abolition of conditional fear after excitotoxic lesions in the basolateral amygdala of rats: absence of a temporal gradient. Behav Neurosci 110:718-726.

Matsumoto RR (1989) GABA receptors: are cellular differences reflected in function? Brain Res Rev 14:203-225.

McGaugh JL, Cahill L, Roozendaal B (1996) Involvement of the amygdala in memory storage: interaction with other brain systems. Proc Natl Acad Sci USA 93:13508-13514.
McKernan MG, Shinnick-Gallagher P (1997) Fear conditioning induces a lasting potentiation of synaptic currents in vitro. Nature 390:607-611.

Milner B (1971) Memory and the medial temporal regions of the brain. In: Biology of memory (Pribram KH , Broadbent DE, eds), pp 29-50. New York: Academic

Miserendino MJ, Sananes CB, Melia KR, Davis M (1990) Blocking of acquisition but not expression of conditioned fear-potentiated startle by NMDA antagonists in the amygdala. Nature 345:716-718.

Moyer Jr JR, Thompson LT, Disterhoft JF (1996) Trace eyeblink conditioning increases CA1 excitability in a transient and learning-specific manner. J Neurosci 16:5536-5546.

Muller J, Corodimas KP, Fridel Z, LeDoux JE (1997) Functional inactivation of the lateral and basal nuclei of the amygdala by muscimol infusion prevents fear conditioning to an explicit conditioned stimulus and to contextual stimuli. Behav Neurosci 111:683-691.

Muramoto K, Ono T, Nishijo H, Fukuda M (1993) Rat amygdaloid neuron responses during auditory discrimination. Neuroscience 52:621-636.

Nadel L, Moscovitch M (1998) Memory consolidation, retrograde amnesia and the hippocampal complex. Curr Opin Neurobiol 7:217-227.

Parent MB, Carlos T, McGaugh JL (1992) Increased training in an aversively motivated task attenuates the memory-impairing effects of posttraining $N$-methyl-D-aspartate-induced amygdala lesions. Behav Neurosci 106:789-797.

Pascoe JP, Kapp BS (1985) Electrophysiological characteristics of amygdaloid central nucleus neurons during Pavlovian fear conditioning in the rabbit. Behav Brain Res 16:117-133.

Phelps EA, Anderson AK (1997) Emotional memory: what does the amygdala do? Curr Biol 7:R311-R314.

Poremba A, Gabriel M (1995) The amygdala is necessary for the initial acquisition but not for maintenance of discriminative avoidance behavior in rabbits. Soc Neurosci Abstr 21:1930.

Poremba A, Gabriel M (1997) Amygdalar lesions block discriminative avoidance learning and cingulothalamic training-induced neuronal plasticity in rabbits. J Neurosci 17:5237-5244.

Quirk GJ, Armony JL, LeDoux JE (1997) Fear conditioning enhances different temporal components of tone-evoked spike trains in auditory cortex and lateral amygdala. Neuron 19:613-624.

Rescorla RA (1967) Pavlovian conditioning and its proper control procedures. Psychol Rev 74:71-80.

Rogan MT, Staubli UV, LeDoux JE (1997) Fear conditioning induces associative long-term potentiation in the amygdala. Nature [Erratum (1998) 391:818] 390:604-607.

Roozendaal B, Koolhaas JM, Bohus B (1993) The central amygdala is involved in conditioning but not in retention of active and passive shock avoidance behavior in male rats. Behav Neural Biol 59:143-149.

Shadmehr R, Holcolmb HH (1997) Neural correlates of motor memory consolidation. Science 277:821-825.

Smith DM, Monteverde J, Schwartz E, Freeman Jr JH, Gabriel M (1998) Amygdalar lesions severely impair discriminative avoidance learning, but not discriminative approach learning in rabbits. Soc Neurosci Abstr 24:1899.

Solomon RL, Wynne LC (1954) Traumatic avoidance learning: the principles of anxiety conservation and partial irreversibility. Psychol Rev 61:353-385.

Squire L, Zola-Morgan S (1991) The medial temporal lobe memory system. Science 253:1380-1386.

Thatcher RW, Kimble DP (1966) Effect of amygdaloid lesions on retention of an avoidance response in overtrained and non-overtrained rats. Psychonomic Sci 6:9-10.

Weisz DJ, Harden DG, Xiang Z (1992) Effects of amygdala lesions on reflex facilitation and conditioned response acquisition during nictitating membrane response conditioning in rabbit. Behav Neurosci 106: 262-273.

Winer BJ (1962) Statistical principles in experimental design. New York: McGraw-Hill.

Zola-Morgan S, Squire LR (1990) The primate hippocampal formation: evidence for a time limited role in memory storage. Science 250: $288-290$. 